\title{
FREE YOUR MIND: BUDDHISM, CAUSALITY, AND THE FREE WILL PROBLEM
}

\author{
by Christian Coseru \\ Zygon, vol. 55, no. 2 (June 2020) \\ (Penultimate draft. Please cite the published version)
}

Abstract. The problem of free will is associated with a specific and significant kind of control over our actions, which is understood primarily in the sense that we have the freedom to do otherwise or the capacity for self-determination. Is Buddhism compatible with such a conception of free will? The aim of this article is to address three critical issues concerning the free will problem: (1) what role should accounts of physical and neurobiological processes play in discussions of free will? (2) Is a conception of mental autonomy grounded in practices of meditative cultivation compatible with the three cardinal Buddhist doctrines of momentariness, dependent arising, and no-self? (3) Are there enough resources in Buddhism, given its antisubstantialist metaphysics, to account for personal agency, self-control, and moral responsibility?

Keywords: Buddhist ethics; causation; consciousness; conscious will; free will; meditation; moral responsibility

"I'm trying to free your mind ... But I can only show you the door. You're the one that has to walk through it ... You have to let it all go. Fear, doubt, and disbelief. Free your mind" - thus urges Morpheus a weary, pummeled, and slightly bewildered Neo uncertain about the end goal of the Matrix training program in the eponymous sci fi blockbuster. In seeking to reach out beyond - or in this case quite literally punch his way through - the insidious and all-pervasive computer-generated simulation we call the matrix, Neo has encountered a formidable obstacle: his own mind. Early on during his training he is as yet unable to tell the difference between the matrix and a mere simulation of it. They are equally immersive and life-like; they have simple rules like gravity; and while plugged into one or the other, there is no way of telling which one is the matrix and which the matrix training program.

The world of appearance, it seems, provides no clues about the real world. Worse still, the world of appearance is forgetfulness-inducing: dwell in it long enough and you will soon forget that the shadowy figures who populate it, not unlike those cast by puppeteers in Plato's Allegory of the Cave, are not real. How is one to negotiate, then, the difference between the two? How does one escape from that simulacrum of reality and draw nearer to the things that are? The answer, at least according to the philosophically syncretic directors of the Matrix, the Wachowski brothers (now sisters), lies in a unique ability of the human mind to imagine alternative possibilities, and to reason counterfactually, or in ways that are remote from how things ordinarily are.

Does counterfactual reasoning suffice for freedom? According to one well established line of thought going back to Kant, addressing the problem of free will requires that we be in a position 
to distinguish between practical and theoretical reason. That is, regardless of whether or not theoretical reason is able to demonstrate freedom, practical reason must assume that freedom is possible for the purpose of effective action (Kant 1996, 5.30). And it is the exercise of practical reason that endows the human mind with the will to overcome forms of conditioning grounded in "preceding time" - specifically, in the complex of causal factors that define who we are as temporal beings bound by the laws of physics and constrained by our psychology (Kant 1996, 5.96-97). For Kant the only kind of freedom such temporally determined beings can experience is psychological. True freedom - what Kant calls transcendental freedom (Kant 1996, 5.97) must be independent of anything empirical if it is to serve as ground for a moral law. It is this latter kind of freedom that allows humans, as self-conscious subjects, to regard their existence "insofar as it does not stand under conditions of time" (Kant 1996, 5.97) as an expression of absolute spontaneity — the sort required for the ability to do otherwise.

Whatever the constitutive features of this practical reasoning capacity may be, it is clear that they emerge quite early in our development. Con- sider, for instance, that children as young as six are already capable of "doing otherwise" or not acting as they please, thus exhibiting an ability to choose a course of action against stated desires (Kushnir et al. 2015; Kushnir 2019; FitzGibbon et al. 2019). This capacity to do otherwise suggests that belief in free will is associated not only with the development of self-control but also, and more importantly, with the acquisition of a basic sense of self. If the ability to reign in our desires and impulses emerges together with, and depends on, basic forms of self-awareness, then loss of self-awareness ought to correlate with diminished self-control. Our folk intuitions certainly favor the view that any kind of selfregulation, self-monitoring, and self-control presupposes awareness of an ability to do otherwise, and to overcome impulse and habit.

One tradition of thought in particular challenges this seemingly inextricable link between the capacity to do otherwise and the sense of agency implicit in that undertaking: Buddhism. Of course, Buddhism is famous for its practices of moral and mental cultivation. But since all Buddhists give universal scope to the no-self doctrine, it is not exactly clear whether these practices require some conception of agency, and, if they do, what this agency entails. For while Buddhism provides ample testimony for the possibility of cultivating to a high degree cardinal virtues such as non-violence, wisdom, compassion, and a general spirit of tolerance, it is unique among the world's great philosophical traditions in articulating a theory of action that, it seems, dispenses altogether with the notion of agent causation. Buddhists pursue what are unmistakably moral ends. And yet there is no stable self or agent who bears the accumulated responsibility for initiating those pursuits, and seemingly no normative framework against which some dispositions, thoughts, and actions are deemed felicitous, and thus worthy of cultivation, while others are not so deemed. It is not surprising, there- fore, to find a near universal lack of agreement about whether something analogous to a notion of free will is to be found in Buddhism.

In the first book-length study to address this problem, Buddhism, Meditation, and Free Will: A Theory of Mental Freedom, Rick Repetti argues that we are now in a better position to offer an answer: not only is there scope for a conception of free will in Buddhism, but the Buddhist contemplative project on the whole may be interpreted as advancing a theory of mental freedom. This is a constructive rather than exegetical project, as Repetti himself acknowledges: the goal is 
not to piece together the theory of free will various Buddhist sources may be read as advancing. Rather, the aim is to develop a theory of autonomy informed by various elements of Buddhist thought and practice (Repetti 2020). Besides textual evidence, Repetti also draws on his own experience as a long-term contemplative practitioner, which he regards as an additional source of evidential sup- port for his theory. And, given the scope of the project, the book offers a sustained critical engagement with free will skepticism and some of its contemporary defenders.

I was pleased when Repetti invited me to write the foreword to his book, given that he first conceived of his project while participating in a National Endowment for the Humanities Summer Institute on cross-cultural investigations of consciousness, which I co-directed with Jay Garfield and Evan Thompson in 2012. As I note there (Coseru 2019), much of the current debate on free will takes place against the backdrop of a growing body of scientific evidence about the brain mechanisms that regulate behavior, which, as some have argued, threaten our deeply entrenched conception of libertarian freedom (Bargh 1997, 2008; Bargh and Chartrand 1999; Passingham and Lau 2006; Passingham, Bengtsson and Lau 2010). Whether this evidence demonstrates that there is no such thing as free will or that, at best, free will is a conscious illusion, however, remains an open question. Nonetheless, the assumption that concepts such as intention, deliberation, decision, and the weighing of reasons are basic may not suffice to allay general anxieties about the explanatory reducibility of the mental states these concepts represent.

That all humans feel a deep sense of unease each time the reality of free will is called into question is, by most psychological accounts of the normal human condition, a given. Unlike nonhuman animals, we are not inexorably bound, at least not in our rational deliberations, by the laws of nature. The most down-to-earth human does things for a reason, even though it is desires and beliefs that ultimately supply those reasons. Indeed, except for certain pathological cases such as schizophrenia, all normal humans enjoy a basic certainty that, as conscious individuals, we are the agents of our own voluntary acts. And yet, despite the compelling and nearly ubiquitous sense that consciousness does cause behavior, and that intention is what sets apart voluntary from involuntary action, the notion that humans are just "conscious automata" (Huxley 1874) has gained significant ground in recent decades as scientific evidence for the unconscious roots of much of our voluntary thought and action continues to accumulate.

Among these new lines of evidence, two in particular stand out. One is associated with Benjamin Libet (Libet et al. 1983), whose experiments with EEG event-related potential appeared to demonstrate that although conscious awareness precedes voluntary action (say, finger movement), it is in turn preceded by brain activity (a neural-level readiness potential) leading up to it. The presence of such an event-related potential for action prior to conscious awareness seemed to suggest that consciousness is either epiphenomenal or acausal. Somewhat troubled by his own findings, Libet eventually came to reject the view that consciousness lacks in any kind of causal efficacy, proposing instead that consciousness' role is primarily either that of exercising a veto power fractions of a second prior to action or of triggering a volitional process to proceed in the execution of final action (Libet 1994). However, Libet found no evidence for the 'trigger' model, thus limiting the role of consciousness to a veto capacity, which he spelled out in terms of a control function. Since there is no logical imperative that such control function be preceded by specific neural activity, and since we must prima facie acknowledge the almost 
universal experience that we do sometimes act freely, it must be the case that conscious mental processes play a causative role on some brain processes (Libet 1999, 55-56).

The second line of evidence comes from experiments involving self- assessments of agency conducted by Daniel Wegner (2002). Wegner's working hypothesis was that the experience of cause and effect should not vary between observing it in external phenomena and experiencing it first-personally. In both cases, it ought to be true that (i) the causal event is prior to what we regard as the effect of that event (the priority principle), (ii) the causal relation between the two events actually obtains (the consistency principle), and (iii) the causal event is the only apparent cause (the exclusivity principle). One experiment involved subjects being asked to move a cursor randomly on a computer screen displaying various objects and to rate their sense that what caused the cursor to stop was their action rather than the experimenter. Since the intentionality ratings in the case where the cursor was stopped by the subject varied only slightly from those where the cursor was stopped by the experimenter ( 56 percent versus 52 percent respectively), the results were interpreted as suggesting that the subjects' own experience of free will can be easily manipulated. In keeping with the consistency principle, Wegner concluded that if our thoughts about acting on an object are consistent with what happens to it, then we believe in our causal capacity to have made it happen.

It is undeniable that these and similar findings testify to the importance that empirical research plays in identifying the brain mechanisms responsible for conscious thought and voluntary behavior, and in providing models for how agency might emerge in the conscious recognition of such intentional actions (Metzinger 2004; Pockett 2006; Jannerod 2006). What is less clear is whether such evidence serves as proof that these mechanism cause, rather than merely correlate with, the sense of control we experience in ongoing actions. As proponents of dynamic theories of intentions (Pacherie 2008; Mele 2009) and accounts of the phenomenology of agency (Horgan 2011; Gallagher 2017) have shown, it is not enough to identify intentions (whether prior or in action) on the basis of their functional role. One must also differentiate them on the basis of the contents they involve, which means that a proper understanding of the exercise of free will in intentional action must consider the dynamic transitions among different types of intentions.

Given these considerations, it is not surprising to find arguments to the effect that empirical science cannot resolve the dispute between compatibilism and incompatibilism if the dispute hinges on what is fundamentally taken to be the meaning of 'control.' For compatibilists, it makes perfect sense to say that we control our actions despite the fact that they are brought about by genetic and environmental factors, if by control we mean the adoption of a reflective standpoint from which we choose among our effective desires (Frankfurt 1971; Dennett 2003, 284). But incompatibilists - who take the view that control means self-formation (which presupposes indeterminacy as a necessary factor) - claim that to insist (as compatibilists do) that actions are determined by impersonal factors is effectively to say that they are beyond our control (van Inwagen 1983; Kane 1996). If the dispute between compatibilists and incompatibilists concerns not the accuracy of our descriptive psychology, but normative claims about meaning, specifically the meaning of such key categories as 'control,' then the question of the meaning of control is fundamental and thus not something that empirical sciences can settle (Ross 2006). 
As the essays that are part of this Author Meets Critics book symposium illustrate, resolving the problem of the meaning of control is far from an easy task given the implications of normative ethical systems for the problem of free will and moral responsibility. The problem is further compounded by common disagreements about the possibility of interpreting the tenets of Buddhist ethics using the vocabulary and normative frameworks of Western ethical discourse. Undeterred by such seemingly insurmountable problems, Repetti thinks the "great confidence" with which philosophers and scientists such as Robert Wright (2017) and Sam Harris (2013, 2014) "speak . . . about the unreality of free will in the light of Buddhism, philosophy, and science" (Repetti 2019, 4), should rather serve as a powerful justification for precisely the project he pursues in his book.

Debates about the reality of free will may be largely confined to the academy. But beliefs about free will or lack thereof, it seems, do have real- world implications. Recent research suggests that subjects primed with statements that call into question the reality of free will are less prone to engage in pro-social behavior (Vohs and Schooler 2008), and that belief in free will typically correlates with higher pro-social and altruistic behavior (Baumeister, Masicampo, and DeWall 2009; Leotti, Iyengar, and Ochsner 2010; Stillman et al. 2010). Such research may be interpreted as simply making the case for the value of believing in free will, leaving questions about the reality of free will open. Surely, free will skeptics will find in it further evidence that the ease with which belief in free will can be manipulated demonstrates its illusory nature. But advocates of the reality of free will may argue that, on the contrary, such experiments in effect demonstrate the ineliminability of intentional agency, without which subjects could neither have been be in a position to choose between alternative possibilities nor call their agency into question. For agency, choice, and control are emergent, higher-order phenomena that supervene on the physical phenomena, but are not reducible to them (List 2019, 64-77).

Repetti appears particularly concerned about the real-world implications of beliefs in free will when he claims that unsuspecting and less philosophically-savvy audiences risk being misled by arguments against free will "into thinking there is no reason for them to engage in reflective deliberation, the weighing of moral reasons and probable consequences, the making of rationally informed decisions, or efforts to enact them" (Repetti 2019, 5). And he takes issue with what he regards as hasty, facile, or dogmatic interpretations of the no-self doctrine - mostly associated with popular purveyors of the mindfulness movement - as providing justification for an agentless conception of human thought and behavior. Undoubtedly, the rejection of an enduring, substantive, and metaphysically distinct self is for many contemporary scientists and philosophers one the most appealing features of Buddhist metaphysics. But that is only half the story, and Repetti joins a group of philosophers (e.g., Albahari 2006; Zahavi 2014; Carpenter 2015; Thompson 2015; Coseru 2020) who in recent years have argued against interpretations of the no-self doctrine as entailing epiphenomenalism about consciousness or the view that mental phenomena lack causal efficacy.

Building on these two sets of presuppositions, Repetti advances a com- plex and nuanced account of mental freedom under the guise of what he calls 'Buddhist Soft Compatibilism' between free will, causation, and the self. Since practices of moral and mental cultivation are of central concern for Buddhists, their pursuit must perforce rest on a particular conception of volitional autonomy, which Repetti regards as "a species of the larger genus of mental autonomy 
or freedom of the mind" (Repetti 2019, 11). When paired with a set of causal-counterfactual principles that support the idea that only causally efficacious entities are ultimately real, these practices ground a particular conception of agency. Repetti calls it the 'agent-self': a wellintegrated, self-regulating, functionally effective, and responsive system. Far from having championed the dissolution of all traces of personal identity, in laying out his Eightfold Path program, argues Repetti, the Buddha aimed to produce 'meditation virtuosos', individuals capable of extraordinary feats of mental freedom far in excess of what conventional conceptions of free will as the capacity to do otherwise entail.

The critical commentaries showcase the challenges of such a project, and provide both criticism and valuable suggestions for how to move the project of Buddhism and the free will problem forward. Gregg Caruso identifies three problematic issues that Repetti must address if his project is to succeed. First, ongoing debates about how to define free will means that equating it with metacognitive awareness of first-level mental states, and with responsiveness to reasons, may be insufficient to ground the kind of control in action (or lack thereof) required for basic desert moral responsibility, which Caruso regards both as the dominant concern of, and the main motivation for, free will skepticism. Second, alternative interpretations of Buddhism as incompatible with conceptions of free will on both determinist and indeterminist grounds (e.g., Strawson 1986, 2017; Goodman 2009, 2017; Blackmore 2013) make Repetti's stance on the possibility of a Buddhist theory of free will less compelling if the question is simply that one may or could mine Buddhist sources for such a theory. Others could and indeed have mined those very sources to make the case for hard incompatibilist or skeptical theories of free will.

Third, Caruso thinks Repetti has not given full consideration to certain influential defenses of free will skepticism (e.g., Pereboom 2001, 2014), and proposes his own 'luck' or 'disappearing agent' account, "according to which agents are left unable to settle whether a decision/action occurs, and hence cannot have the control in action required for moral responsibility" (Caruso 2012, 2020). Drawing on Zimmerman's (2006) work on Buddhism and violence, Caruso offers an innovative, if not altogether unproblematic, way of reconciling Buddhist ethics with his public health- quarantine model for addressing criminal behavior (Caruso forthcoming). He argues, rightly in my view, that Buddhist ethics discourages actions grounded in reactive dispositions such as anger, hatred, and resentment, but assumes such reactive dispositions preclude the conception of a morally responsive agency (see Coseru 2017a for an alternative account). The motivation for this proposal stems from Caruso's view that in seeking to understand what Buddhism can contribute to the contemporary problem of free will, we should be looking to its practical moral teachings rather than its metaphysics of personal identity.

David Cummiskey takes up the issue whether the conception of mental autonomy Repetti defends is compatible with the three cardinal Buddhist doctrines of momentariness, dependent arising, and no-self. He thinks that it is not and, moreover, that the conception of free will Repetti has in mind is practically indistinguishable from Kantian conceptions of autonomy. According to Cummiskey, since "Kantian autonomy is incompatible with the doctrine of no-self" Repetti confronts a dilemma: "either defend free will without autonomy or more fully develop a non-Kantian conception of autonomy" (Cummiskey 2020). In suggesting the latter as a more fruitful way to address the Buddhism and free will problem, Cummiskey also offers a preliminary two-part solution: first, a critique of the view that higher-order or metacognitive 
control provides justification for a responsibility entailing conception of free will (associated with the work of Frankfurt (1971)); and second, a defense of minimalist conceptions of the self (drawing on work by Velleman (2006)) that is in keeping with the Buddhist no-self doctrine. Cummiskey is in broad agreement with Repetti that "as a mechanism of meta-cognitive control" meditation must also be "reason-responsive" or "Dharma-responsive" (Cummiskey 2020). But he takes issue with Repetti's apparent failure to "incorporate the interdependent relationship among meditation, insight, and virtue into his Buddhist conception of free will" (Cummiskey 2020) - an interdependence that is actually entailed by the relational conception of agency at the heart of Buddhist metaphysics. Whether Repetti's insistence that contemplative practice foregrounds a sense of being a kind of executive awareness that is irreducible to the five aggregates (of body, sensation, perception, volition, and consciousness) brings him closer to Kant than the Buddha remains, however, an open question. If Repetti understands this executive awareness to be analogous to what Buddhist philosophers in the tradition of Dignāga and Dharmakirti regard as the reflexive nature of awareness (svasamvedana, svasamvitti), which it seems he does (Repetti 2019,97), then his conception of agency does draw sufficiently close to influential developments in Buddhist philosophy of mind to keep him firmly in the Buddha's camp.

Lastly, Karin Meyers provides a detailed critique of Repetti's idiosyncratic use of the notion of "mental freedom," which she interprets as analogous to the Pa li concept of ceto-vimutti (lit. "freedom of the heart" or "liberation of mind"). Meyers agrees with Repetti that while the Buddhist path both requires and aims to enhance metavolitional control, the goal is habituation or (re-)habituation - broadly understood as the twin task of rooting out defilements by means of calm abiding and concentration — not mental freedom simpliciter. Moreover, as she rightly points out, this "process is also deeply somatic - a dimension of Buddhist meditative praxis that Repetti does not address" (Meyers 2020). The freedom in question is of the loving heart or better still of the loving heart-mind, since the terms typically translated as 'mind' or 'consciousness', the Pa $7 i$ ceto and Sanskrit citta, cut across the mind-body or heart-mind dichotomy: one points to the center of one's chest, rather than the head, when referring to citta. Likewise, one speaks of dispositions or volitions (cetana) not as pure intentional acts, but as a "kind of executive function ... that involves the entire personality" (Meyers 2020). Meyers is less worried about the need for grounding agency or the sources of autonomy in an 'ontological-causal reality', even as she agrees with Repetti that the kind of control Buddhist adepts are supposed to command far exceeds what Western conception of free will or mind over matter entail. What motivates her view is confidence "that Buddhists have the resources to account for personal agency, selfcontrol, and moral responsibility in a way that is neutral with respect to the truth of causal determinism" (Meyers 2020, see also Meyers 2014). Furthermore, since Buddhists are mainly interested in prospective freedom rather than retrospective responsibility, the requirement that reasons one shows responsiveness to (on a reason-responsive account of moral responsibility) be one's own rather than someone else's is less stringent. Meyers is also in broad agreement with Cummiskey that ultimately what matters is that these are good reasons that promote freedom from suffering, rather than who first originated them. The freedom thus achieved is not of the mind. It is not mental freedom, but rather freedom from unwholesome habits such as greed, hatred, and delusion (including the delusion of a permanent and stable self), which are inextricable mental processes. 
Judging from the important questions raised by the critics and Repetti's reply, two issues in particular stand out in this cross-cultural philosophical conversation: (i) whether a version of soft compatibilism such as Repetti proposes withstands any and all the main arguments for free will skepticism, and (ii) whether the specific conception of mental freedom or autonomy Repetti has in mind finds support in the Buddhist literature. As I have argued at length elsewhere (Coseru 2017a, 2017b), causal determinism was far less an issue of concern for the historical Buddha than the fatalism of the $\bar{A}$ jīvikas. For in removing all trace of effort from human actions, the latter were accused of having rendered the ethical life meaningless. To advocate for such a view is effectively to argue that neither defilement nor purification have any cause or condition. No action is ever voluntarily undertaken either by oneself or by another. Such a view of humans as lacking power, energy, and steadfastness is far more consequential than claiming actions are causally determined or random. In condemning this view, the Buddha emphasizes above all the efficacy of individual effort. That we are able to deliberate about any matter whatsoever, and eventually to take a first step, shows that there is an element of initiative, that one either strives to overcome some resistance or to reach the sort of reflective equilibrium that comes with understanding and insight (Ánguttara Nikāya 6.38, in Bodhi 2012, 901).

Should this rejection of fatalism be taken to mean that the Buddha is championing freedom of the will? More importantly, is there a notion of personal autonomy at work in the Buddha's clear admonition to his followers to jettison the extremes of both determinism and indeterminism, and devote themselves instead to an ethical and contemplative life in the pursuit of liberation? If we consider the lives of the great majority of people, moved, as they often are, by short-term, pragmatic goals, unsure and uncertain about their choices (let alone their consequences), lofty notions of personal freedom (the sort libertarians often have in mind) might seem wholly inappropriate, if not altogether unrealistic. What, then, explains the appeal of a life in the pursuit of moral and mental cultivation, if the end goal is not simply the cessation of suffering, but dissolution of the subject of that suffering: the agent herself? Are the Buddhist Personalists right after all to insist that if the aggregates (of body, sensation, perception, volition, and consciousness) operate in a person constitutive way, then persons are ultimately real? (Priestly 1999).

Expressions of self-concern and concern about the consequences of one's actions are a ubiquitous feature of Buddhist teachings. And the value placed on shame and apprehension suggests that the Buddha does favor a conception of responsibility and moral self-regard for those pursuing the Eightfold Path. The question, then, is whether these morally reactive attitudes, whether wholesome or unwholesome, are impersonal mental factors or depend on a phenomenal conception of first-personal agency that is ultimately irreducible. In short, if choice and the sense of control and ownership of action are not illusory, then one must contend that agency may in effect be built into the very fabric of lived experience.

The critical commentaries gathered here, along with Repetti's response, address these and several other issues in great detail. First presented at an "Author Meets Critics" invited session on Repetti's book that I organized for the Eastern Division of the American Philosophical Association meeting, held in New York, January 7-10, 2019, these papers are published here in their final, revised format. Whether or not one agrees with the critical points they raise, the 
arguments adduced in their support undoubtedly offer a compelling example of the value of systematic cross-cultural philosophy.

\section{REFERENCES}

Albahari, Miri. 2006. Analytic Buddhism: The Two-Tiered Illusion of Self. New York, NY: Palgrave Macmillan.

Bargh, John A. 1997. "The Automaticity of Everyday Life.” In Advances in Social Cognition, edited by R. S. Wyer \& T. K. Srull, 10: 1-61. Mahwah, NJ: Erlbaum.

- 2008. "Free Will Is Unnatural." In Psychology and Free Will, edited by J. Baer, J.C. Kaufman, \& R. F. Baumeister, 128-54. New York, NY: Oxford University Press.

Bargh, John A., and T. L. Chartrand. 1999. "The Unbearable Automaticity of Being." American Psychologist 54 (7): 462-79.

Baumeister, R. F., E. J. Masicampo, and C. N. DeWall. 2009. "Prosocial Benefits of Feeling Free: Disbelief in Free Will Increases Aggression and Reduces Helpfulness." Personality and Social Psychology Bulletin 35: 260-68.

Blackmore, Susan. 2013. "Living without Free Will." In Exploring the Illusion of Free Will and Moral Responsibility, edited by Gregg D. Caruso, 161-76. Lanham, MD: Lexington Books.

Bodhi, Bhikkhu, ed. and trans. 2012. The Numerical Discourses of the Buddha: A Translation of the Ainguttara Nikāya. Boston, MA: Wisdom Publications.

Carpenter, Amber. 2015. "Persons Keeping Their Karma Together: The Reasons for the Pudgalaväda in Early Buddhism." In The Moon Points Back, edited by Koji Tanaka, Yasuo Deguchi, Jay L Garfield, and G. Priest, 1-44. New York, NY: Oxford University Press.

Caruso, Gregg D. 2012. Free Will and Consciousness: A Determinist Account of the Illusion of Free Will. Lanham, MD: Lexington Books.

- 2020. "Buddhism, Free Will, and Punishment: Taking Buddhist Ethics Seriously." Zygon: Journal or Religion and Science 55: 474-496.

_forthcoming. "The Public Health-Quarantine Model.” In Oxford Handbook of Moral Responsibility, edited by Dana Kay Nelkin and Derk Pereboom. New York, NY: Oxford University Press.

Coseru, Christian. 2017a. "Freedom from Responsibility: Agent-neutral Consequentialism and the Bodhisattva Ideal." In Buddhist Perspectives of Free Will: Agentless Agency, edited by Rick Repetti, 92-105. New York, NY: Routledge. 
Coseru, Christian. 2017b. "Breaking Good: Moral Agency, Neuroethics, and the Spontaneity of Com- passion." In A Mirror Is for Reflection: Understanding Buddhist Ethics, edited by Jake H. Davis, 109-28. New York, NY: Oxford University Press.

Coseru, Christian. 2019. "Foreword” to Rick Repetti's Buddhism, Meditation, and Free Will: A Theory of Mental Freedom, x-xii. New York, NY: Routledge.

Coseru, Christian. 2020. "Reasons and Conscious Persons." In Derek Parfit's Reasons and Persons: An Introduction and Critical Inquiry, edited by Andrea Sauchelli, 160-86. London: Routledge.

Cummiskey, David. 2020. "Ego-less Agency: Dharma-Responsiveness without Kantian Autonomy." Zygon: Journal of Religion and Science 55: 497-518.

Dennett, Daniel C. 2003. Freedom Evolves. New York, NY: Viking.

FitzGibbon, L., H. Moll, J. Carboni, R. Lee, and M. Dehghani. 2019. "Counterfactual Curiosity in Preschool Children." Journal of Experimental Child Psychology." 183: 146-57.

Frankfurt, Harry. 1971. "Freedom of the Will and the Concept of a Person." Journal of Philosophy 68 (1): 5-20.

Gallagher, Shaun. 2017. Enactivist Interventions: Rethinking the Mind. New York, NY: Oxford University Press.

Goodman, Charles. 2009. Consequences of Compassion: An Interpretation of Defense of Buddhist Ethics. New York, NY: Oxford University Press.

- 2017. "Uses of the Illusion of Agency: Why Some Buddhists Should Believe in Free Will." In Buddhist Perspectives on Free Will, edited by Rick Repetti, 34-43. New York, NY: Routledge.

Harris, Sam. 2013. Free Will. New York, NY: Free Press.

- 2014. Waking Up: A Guide to Spirituality without Religion. New York, NY: Simon and Schuster.

Horgan, Terry. 2011. "The Phenomenology of Agency and Libet Results.” In Conscious Will and Responsibility, edited by Walter Sinnott-Armstrong, 159-72. New York, NY: Oxford University Press.

Huxley, Thomas H. 1874. "On the Hypothesis that Animals Are Automata, and Its History." Fortnightly Review 16: 555-80. Reprinted in Method and Results: Essays by Thomas H. Huxley (D. Appleton, 1898). 
Jeannerod, Marc. 2006. "Consciousness of Action as an Embodied Consciousness." In Does Consciousness Cause Behavior? Edited by Susan Pockett, William P. Banks \& Shaun Gallagher, 25-38. Cambridge, MA: MIT Press.

Kane, Robert H. 1996. The Significance of Free Will. Oxford: Oxford University Press.

Kant, Immanuel. 1996. Critique of Practical Reason. In Practical Reason, translated and edited by

Mary Gregory, 137-271. Cambridge: Cambridge University Press.

Kushnir, T. 2019. "The Developmental and Cultural Psychology of Free Will." Philosophy Compass 13(11): 1-17.

Kushnir, T., A. Gopnik, N. Chemyak, E. Seiver, and H. M. Wellman, 2015. "Developing Intuitions about Free Will between Ages Four and Six." Cognition 138: 79-101.

Leotti, L. A., S. S. Iyengar, and K. N. Ochsner. 2010. "Born to Choose: The Origins and Value of the Need for Control." Trends in Cognitive. Science 14: 457-63.

Libet, Benjamin. 1994. "A Testable Mind-Brain Field Theory.” Journal of Consciousness Studies 1: 119-26.

- 1999. "Do We Have Free Will?" Journal of Consciousness Studies 6(8-9): 47-57. Libet, Benjamin, C. A. Gleason, E. W. Wright, and D. K. Pearl. 1983. "Time of Conscious Intention to Act in Relation to Onset of Cerebral Activity (Readiness-Potential)." Brain 106: $623-42$.

List, Christian. 2019. Why Free Will Is Real. Cambridge, MA: Harvard University Press.

Mele, Alfred R. 2009. Effective Intentions: The Power of Conscious Will. New York, NY: Oxford University Press.

Metzinger, Thomas 2004. Being No One: The Self-Model Theory of Subjectivity. Cambridge, MA: MIT Press.

Meyers, Karin. 2014. "Free Persons, Empty Selves: Freedom and Agency in Light of the Two Truths." In Free Will, Agency, and Selfhood in Indian Philosophy, edited by Matthew Dasti and Edwin F. Bryant, 41-67. New York, NY: Oxford University Press.

- 2020. "Mental Freedom and Freedom of the Loving Heart: Free Will and Buddhist Meditation." Zygon: Journal of Religion and Science 55: 519-539.

Pacherie, Elizabeth. 2008. "The Phenomenology of Action: A Conceptual Framework." Cognition 107(1): 179-217. 
Passingham, Richard, and Hakwan Lau. 2006. "Free Choice and the Human Brain." In Does Consciousness Cause Behavior? edited by Susan Pockett, William P. Banks \& Shaun Gallagher, 53-72. Cambridge, MA: MIT Press.

Passingham, Richard, S. Bengtsson, and Hakwan Lau. 2010. "Medial Frontal Cortex: From SelfGenerated Action to Reflection on One's Own Performance." Trends in Cognitive Science 14: $16-21$.

Pereboom, Derk. 2001. Living without Free Will. Cambridge, MA: Cambridge University Press.

- 2014. Free Will, Agency, and Meaning in Life. New York, NY: Oxford University Press.

Pockett, Susan. 2006. “The Neuroscience of Movement." In Does Consciousness Cause Behavior? edited by Susan Pockett, William P. Banks and Shaun Gallagher, 9-24. Cambridge, MA: MIT Press.

Priestley, Leonard. 1999. Pudgalaväda Buddhism: The Reality of the Indeterminate Self. Toronto: Centre for South Asian Studies, University of Toronto.

Repetti, Rick. 2019. Buddhism, Meditation, and Free Will. New York, NY: Routledge.

- 2020. "A Defense of Buddhism, Meditation, and Free Will: A Theory of Mental Freedom.” Zygon: Journal of Religion and Science 55: 540-564.

Ross, Peter W. 2006. "Empirical Constraints on the Problem of Free Will." In Does Consciousness Cause Behavior? edited by Susan Pockett, William P. Banks \& Shaun Gallagher, 125-44. Cambridge, MA: MIT Press.

Stillman, T. F., R. F. Baumeister, K. D. Vohs, N. M. Lambert, F. D. Fincham, and L. E. Brewer. 2010. "Personal Philosophy and Personnel Achievement: Belief in Free Will Predicts Better Job Performance.” Social Psychological and Personality Science 1: 43-50.

Strawson, Galen. 1986. Freedom and Belief. New York, NY: Oxford University Press.

- 2017. "Free Will and the Sense of Self." In Buddhist Perspectives of Free Will: Agentless Agency? edited Rick Repetti, 72-83. New York, NY: Routledge.

Thompson, Evan. 2015. Waking, Dreaming, Being: Self and Consciousness in Neuroscience, Meditation, and Philosophy. New York, NY: Columbia University Press.

van Inwagen, Peter. 1983, An Essay on Free Will, Oxford: Clarendon Press.

Velleman, J. David. 2006. "Identification and Identity." In Self to Self: Selected Essays, 330-60. Cambridge: Cambridge University Press. 
Vohs, Kathleen D., and Jonathan W. Schooler. 2008. "The Value of Believing in Free Will: Encouraging a Belief in Determinism Increases Cheating." Psychological Science 19(1): 49-54.

Wegner, Daniel M. 2002. The Illusion of Conscious Will. Cambridge, MA: MIT Press.

Wright, Robert. 2017. Why Buddhism Is True: The Science and Philosophy of Meditation and Enlightenment. New York, NY: Simon and Schuster.

Zahavi, Dan. 2014. Self and Other: Exploring Subjectivity, Empathy, and Shame. Oxford: Oxford University Press.

Zimmermann, Michael. 2006. "Only a Fool Becomes a King: Buddhist Stances on Punishment." In Buddhism and Violence, edited by Michael Zimmermann, 213-42. Lumbini, Nepal: Lumbini International Research Institute. 